\title{
Analysis of ankle inversion sprain injury mechanism from accidental injury cases captured in televised basketball matches
}

\author{
KM Chan ${ }^{1}$, Sophia CW Ha ${ }^{2 *}$, Daniel TP Fong ${ }^{3}, \mathrm{KM} \mathrm{Chan}^{2}$ \\ From 4th Congress of the International Foot and Ankle Biomechanics (i-FAB) Community \\ Busan, Korea. 8-11 April 2014
}

\section{Introduction}

The aim of this study was to use model-based image matching method (MBIM) to study ankle inversion sprain injury mechanism from basketball cases. MBIM can be used to understand the injury mechanism quantitatively by analyzing the three-dimensional human motion [1].

\section{Methods}

An ankle inversion sprain injury occurred in a televised basketball match was found from the internet. The videos were transformed into uncompressed AVI image sequence by using Adobe Premiere Pro (CS4, Adobe Systems Inc, San Jose, California). Then the image sequences were synchronized and rendered into $1-\mathrm{Hz}$ video sequences by Adobe After-Effects (CS4, Adobe Systems Inc). 3-dimension animation software Poser 4 and Poser Pro Pack (Curious Labs Inc, Santa Cruz, California) were used to perform the matching part. Virtual environment was built according to the real dimensions of a basketball court and it was manually matched to the background for each frame in every single camera view. The skeleton model from Zygote Media Group Inc. (Provo, Utah) was used to match with the athlete. The segment dimensions were adjusted according to the subject's height. The skeleton matching started with the hip, thigh, shank segment and then distally matched the foot and toe segments frame by frame. The ankle time histories were input into Microsoft Excel (Microsoft Office, Microsoft, US) to calculate the velocity-related information.

\section{Results}

The peak inversion in this case lies within the range $\left(48^{\circ}-142^{\circ}\right)$ obtained in previous studies [1]. Different from previous studies [1], plantarflexion is found at the time of peak ankle inversion during the injuring motion.

\section{Conclusion}

The analysis of basketball ankle inversion ligamentous sprain case was done and compared with previous studies. Since no basketball cases have been analyzed before, so more basketball cases should be analyzed by MBIM in order to understand the real injury mechanism.

Table 1 Peak value of the ankle angles and velocities (inversion, internal rotation and plantarflexion) were shown in the table below. The lowest row indicates the duration of the ankle sprain injury.

\begin{tabular}{ll}
\hline Max. Inversion angle (deg) & 110 \\
\hline Max. Inversion velocity (deg/sec) & 2916. \\
\hline Time of peak inversion (sec) & 0.24 \\
\hline Max. Internal rotation angle (deg) & 56 \\
\hline Max. Internal rotation velocity (deg/sec) & 551 \\
\hline Time of peak internal rotation (sec) & 0.52 \\
\hline Max. Plantarflexion angle (deg) & 32 \\
\hline Max. Plantarflexion velocity (deg/sec) & 580 \\
\hline Time of peak plantarflexion (sec) & 0.40 \\
\hline Whole duration (sec) & $0.52 \mathrm{~s}$ \\
\hline
\end{tabular}

\footnotetext{
* Correspondence: sophiaha@cuhk.edu.hk

${ }^{2}$ Department of Orthopaedics and Traumatology, Prince of Wales Hospital,

Faculty of Medicine, The Chinese University of Hong Kong, Hong Kong

Full list of author information is available at the end of the article
} 


\section{Authors' details}

'Division of Biomedical Engineering, Department of Electronic Engineering,

The Chinese University of Hong Kong, Hong Kong. ${ }^{2}$ Department of

Orthopaedics and Traumatology, Prince of Wales Hospital, Faculty of

Medicine, The Chinese University of Hong Kong, Hong Kong. ${ }^{3}$ School of

Sport, Exercise and Health Sciences, Loughborough University, Leicestershire

LE11 3TU, UK.

Published: 8 April 2014

\section{Reference}

1. Fong DTP, Ha SCW, Mok KM, Chan CWL, Chan KM: Kinematics analysis of ankle inversion ligamentous sprain injuries in sports - five cases from televised tennis competitions. The American Journal of Sports Medicine 2012, 40(11):2627-2632.

doi:10.1186/1757-1146-7-S1-A30

Cite this article as: Chan et al:: Analysis of ankle inversion sprain injury mechanism from accidental injury cases captured in televised basketball matches. Journal of Foot and Ankle Research 2014 7(Suppl 1): A30.

Submit your next manuscript to BioMed Central and take full advantage of:

- Convenient online submission

- Thorough peer review

- No space constraints or color figure charges

- Immediate publication on acceptance

- Inclusion in PubMed, CAS, Scopus and Google Scholar

- Research which is freely available for redistribution

Submit your manuscript at www.biomedcentral.com/submit 